\title{
HYDROPROCESSING MICROALGAE DERIVED HYDROTHERMAL LIQUEFACTION BIO-CRUDE FOR MIDDLE DISTILLATE FUELS PRODUCTION - A REVIEW
}

\author{
B. Bello-Zakari*

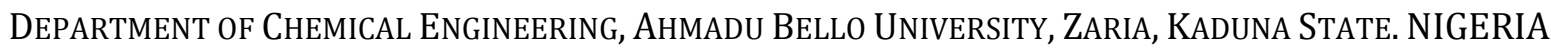 \\ E-mail address: bzakari@gmail.com
}

\begin{abstract}
Bio-crude, a biomass derived oil similar to petroleum crude in properties, can be produced from microalgae via hydrothermal liquefaction (HTL) and upgraded to middle distillates fuels by hydroprocessing which is a very common refinery technology. This paper reviews available literature on HTL of microalgae and the subsequent upgrade of the bio-crude into middle distillate fuels via hydroprocessing. Experimental and process simulation results from different studies were used to explore the differences and similarities between the bio-crude and conventional crude; the methods and process conditions for hydroprocessing the bio-crude; the products obtainable, their compositions \& properties; as well as the inputs required for modelling and simulation of the process. The review illustrates that the same fuels (of almost the same properties) can be produced from the biocrude as from petroleum crude; the process conditions depend on the required product distribution (maximum diesel or kerosene/jet range fuels); and the process is characterized by much higher hydrogen consumption than hydro processing conventional crude.
\end{abstract}

Keywords: Hydroprocessed-renewable-diesel (HRD), hydroprocessed-renewable-jet (HRJ), modelling and simulation, Aspen Plus.

\section{INTRODUCTION}

Microalgae are considered to be one of the most viable feedstock for biofuels production in view of addressing concerns over sustainability of supply and environmental degradation associated with the use of fossil fuels. Microalgae, widely recognised as a good third-generation biofuel [23] feedstock, offer sustainability of supply; do not require arable land and clean water for cultivation; can multiply much faster than other crops $[2,26]$ and serve as very efficient systems for converting $\mathrm{CO}_{2}$ into biomass [22] via $\mathrm{CO}_{2}$ fixation [24]. Due to these advantages studies into the application of microalgae for the production of different biofuels have been on the increase in recent times $[1,4,5,7,10,12,14,15,26,27,35$ - 40]. One of these approaches is to produce a range of transportation fuels from a single feedstock of microalgae synonymous to what is obtainable in the conventional crude-oil refineries. To achieve this, biocrude which is similar to conventional crude oil in physicochemical properties is produced from microalgae via liquefaction. The microalgae liquefaction enables the use of the whole microalgae biomass, contrary to lipid based processes which only utilize some part of it (like production of diesel via transesterification of microalgal oil). Hence microalgae liquefaction has the potential to produce higher yield of fuel per unit microalgae than the other methods in used. Furthermore, since the whole cell is used for the bio-crude production, it is not mandatory to grow high lipid microalgae [4].

Microalgae liquefaction is achieved either via fast pyrolysis or HTL. Both fast pyrolysis and HTL produce bio-crude at relatively high temperatures, by breaking down the constituent molecules of the microalgae into their elemental components [3]. The main difference between fast pyrolysis and HTL is that the former requires the feedstock to be almost completely dry, while the latter utilizes a feedstock with very high moisture content.

This ability to handle feedstock with high moisture content gives HTL an edge over fast pyrolysis and 
makes it a promising emerging technology with high prospect in microalgae conversion to fuels. HTL in general is especially suited for conversion of wet feedstock since the feed to the HTL process is water based slurry [39] and the reaction takes place in an aqueous medium. Consequently, it fits very well into the overall process of microalgae conversion to biocrude, because the microalgae is cultivated in an aqueous medium, which can subsequently be utilized as the HTL reaction medium. Additionally, because microalgae is grown in a very dilute medium the dewatering and drying steps take up a significant percentage of the total energy in the overall microalgae to fuel process. Therefore, avoiding the energy intensive drying step creates an opportunity for energy savings in the overall process [2].

Furthermore, HTL yields a relatively higher quality bio-crude (due to lower nitrogen content) with a higher energy and lower moisture content than fast pyrolysis [31].

Hydroprocessing has been identified as the best method for upgrading bio-crude oil into transportation fuels generally. Hydro processing (HDP) involves hydrotreatment (HDT), as a pretreatments step to improve the quality of the biocrude and make it suitable for further processing, and hydrocracking (HDC) to process the oil into the required finished products in the same way as crude oil, using the same technology. The finished products obtained referred as bio-derived fuels or bio-fuels are hydroprocessed renewable fuels like hydroprocessedrenewable-diesel (HRD) and hydroprocessedrenewable-jet (HRJ) fuels. Hydroprocessed renewable fuels are considered the most likely alternatives to replace conventional fuels, because they are very similar in properties and are directly applicable on current engines without any modification on the fuel system, distribution and/or the storage facilities [4].

Both HTL and hydroprocessing the HTL bio-crude have been considerably studied and well documented in literature $[1,4-12,14,27,28,32-40]$, especially in recent times due to the renewed interest in the utilisation of microalgae as a sustainable feedstock for biofuels production. The succeeding sections of the paper discuss the HTL of microalgae and hydroprocessing the bio-crude in more details. Previous studies were used to explore the differences between the HTL bio-crude and conventional crude oil; as well as the resulting products and their corresponding compositions.

\section{HYDROTHERMAL LIQUEFACTION (HTL) OF WHOLE MICROALGAE BIOMASS}

HTL is a thermochemical process in which very hot water at subcritical temperatures between 250 $350^{\circ} \mathrm{C}$, under very high pressure condition $(5-20$ $\mathrm{MPa}$ ), is used to breakdown the constituent molecules of an organic material into their elemental constituents. The process, which involves complex sequences of reactions, occurs in an aqueous medium within a residence time of $0.2-1.0 \mathrm{hr}$ [3]. Figure 1 shows a possible mechanism of the HTL reaction [11].

\subsection{The Hydrothermal Liquefaction (HTL) Process}

In the HTL process, when the pressurized microalgae containing up to $80 \%$ water is subjected to subcritical temperatures, the water in condensed phase is used to convert the whole biomass into primarily liquid product (the bio-crude); and two other products some gases and solid residue $[4-8,10-12,14-16$, $19,27,28,33,35,37-40]$. The bio-crude consists of a hydrophobic oil phase with reduced oxygen content compared to the parent material (about $10-18 \%$ less) and an aqueous phase. The three main constituents of microalgae are proteins, lipids and carbohydrates and their fraction relative to the total biochemical composition is highly species and growth conditions dependent [37]. Bio-crude is produced from all the constituents [39], including non-lipid cellular components thereby increasing the yields in excess of the cell lipid content [2]. The lipid portion or triglyceride is hydrolysed into free fatty acids, the carbohydrate portion converted to phenols; while the hydrolysis of proteins yield amino acids [33]. Notably, however a higher lipid content can serve as an added advantage because it increase the yield of bio-crude by hydrolysing into free fatty acids, and improve the quality of bio-crude, which makes the subsequent upgrading process easier [4]. On the other hand, high protein content can serve as a disadvantage by yielding amino acids [33]. This is because the amino acids subsequently produce nitrogen containing compounds like amines and amides after decarboxylation and deamination, and also decompose into other nitrogen-containing rings such as indole and quinoline [33].

HTL as a biomass conversion process has a significant advantage of high energy efficiency [2] and high carbon conversion which can be up to $85 \%$ [4], but the high content of nitrogen containing compounds is a key problem associated with the bio-crude. The process also has a downside of requiring high capital 
cost (higher than fast pyrolysis) due to high pressure requirement [3].

\subsection{The whole microalgae HTL Products}

The products of HTL reactions are generally classified into gaseous, solids and liquid bio-crude. The biocrude which constitute the oil-phase and the watersoluble products dictate its yield and physicochemical properties [33]. Like conventional crude oil, the biocrude is a complex mixture of hydrocarbons of various molecular weights, and liquid organic materials. The hydrocarbons are mostly alkanes, cycloal kanes and various aromatics, while the other organic materials are mostly heteroatoms - nitrogen, oxygen, sulphur, halogens, and trace amounts of metals such as iron, nickel copper and vanadium $[10 ; 13 ; 14 ; 33]$. The biocrude obtained from the HTL of Spirulina microalgae by Jena and Das [5], was shown to contain alkanes $\left(\mathrm{C}_{5}\right.$, $\mathrm{C}_{7}$, and $\mathrm{C}_{17}$ ), decanoic acids, carboxylic acids, alcohols, amines, ketones, phenolic compounds, indole, cyclohexane, toluene, benzene, and methyl esters. Similarly, the GC-MS results on the bio-crudefrom HTL of microalgae [33] shows six distinctive categories of compounds it contained, by functional group:

(1) Monoaromatics and their derivatives, such as benzene/Toleune/Styrene, methylbenzene, Cholesterol, Cholestene, Vitamin E, and phenol;

(2) Aliphatic compounds (Alkanes/alkenes) like Hexadecane/Hexadecene,

Heptadecane/heptadecene,

Pentadecane/Heptadecene,

Pentadecane/pentedecene, Phytane/phytene, Docosane \& Cholastane, Eicosane, Coprostane, Tricontane, Hentriacontane and Dotriacontane;

(3) Fatty acids, such as hexadecanoic acid, Myristic acid/Myristoleic acid, Palitic acid/Palmitoleic acid, Stearic acid/Oleic acid,Tetredecanoic \&
Octadecanoic acid, Arachidic acid and Ecosapentanoic acid;

(4) Nitrogen containing compounds, such as amines, amides, Piperidines, Indoles, Pyridines, Pyrazines, and Pyrrolidinones;

(5) Polyaromatics like Naphthalene, Quinoline, Indene, Anthracene \& Phenanthrene, Pyrene \& Carbazole and Fluorene; and

(6) Other oxygen containing compounds, such as alcohols, aldehydes, ketones, Esters, Acetic acid and Furans.

Also Figure 2 shows the individual molecular components in the bio-oil obtained from the HTL of the microalga Nannochloropsis sp. [12]

\subsection{Physicochemical properties of the HTL bio-crude}

The HTL bio-crude is generally a viscous oil, similar to conventional crude oil in properties. But its specific physicochemical properties are subject to its exact compositions, which in turn strongly depends on the microalgae species used as the HTL feedstock and its composition [12]; as well as the exact process conditions under which the reaction is conducted [7]. This is essentially similar to conventional crude where the exact compositions depend on the specific crude oil in question. Table 1 shows the range within which the compositions of a conventional crude generally fits and the corresponding values for HTL bio-crude derived from different microalgae species.

However, the significant amounts of heteroatoms (specifically nitrogen \& oxygen, and sulphur to a lesser extent) contained in the bio-crude, are generally much higher than found in crude oil, and varies with microalgae composition as shown in Table 1. These heteroatoms give the bio-crude additional characteristics different from conventional crude and which can lead to operational problems and technical failure of process equipment if not addressed.

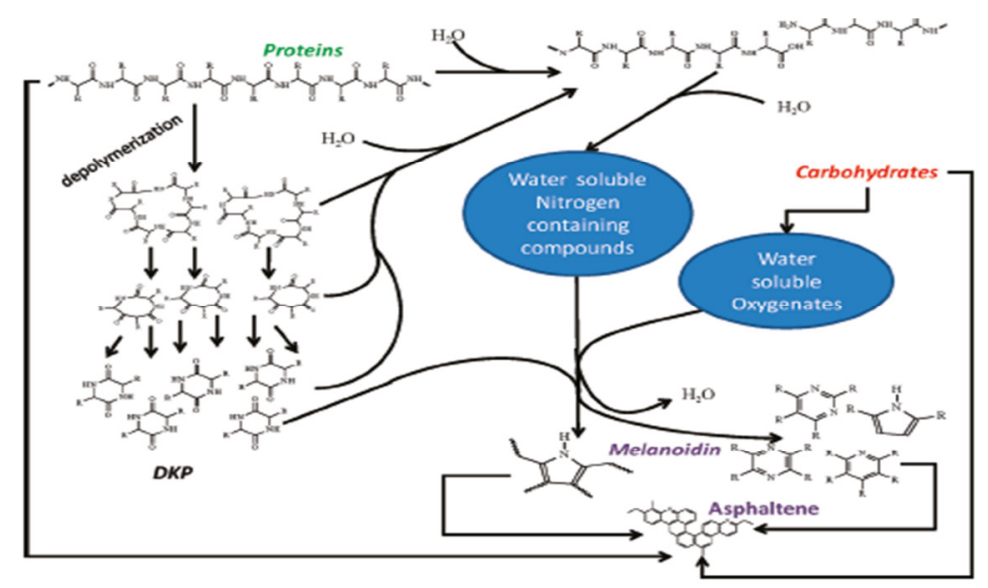

Figure 1: Possible mechanism of HTL oil formation from proteins/carbohydrates [11] 


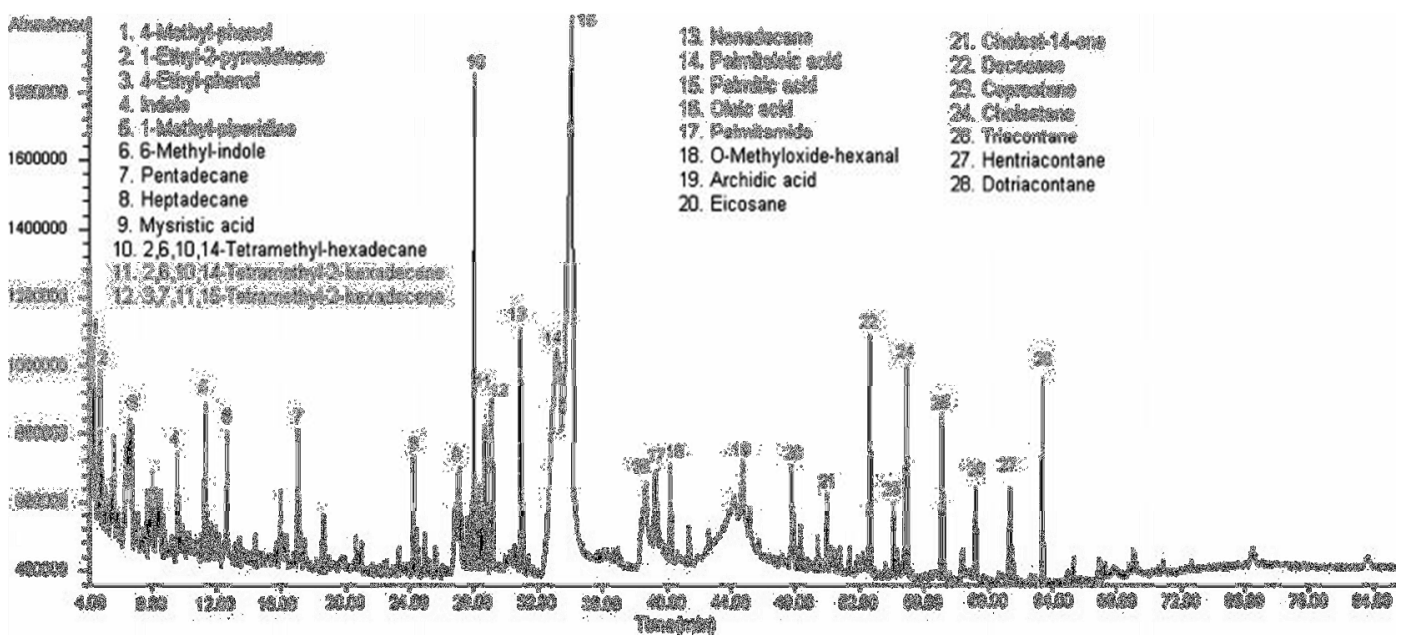

Figure 2: Molecular components in the bio-crude obtained from the HTL of Nannochloropsis sp. [12]

Table 1: Elemental compositions and properties of heavy crude oil and HTL bio-crude from different microalgae species

\begin{tabular}{|c|c|c|c|c|c|c|c|}
\hline $\begin{array}{c}\text { Elemental } \\
\text { compositions (\%) }\end{array}$ & $\begin{array}{c}\text { Crude oil } \\
\text { [13;28; } \\
38]\end{array}$ & $\begin{array}{c}\text { Typical } \\
\text { microalgae } \\
{[31 ; 28]}\end{array}$ & $\begin{array}{c}\text { Spirulinasp } \\
{[5 ; 10]}\end{array}$ & $\begin{array}{c}\text { Mixed algae } \\
{[5]}\end{array}$ & $\begin{array}{l}\text { Dunaliellasp } \\
\qquad(7 ; 15]\end{array}$ & Nannochloropsissalina[19] & Desmodesmussp[38] \\
\hline Carbon & $83-87$ & $70-78.7$ & $68.3-69.37$ & $72.97-74.37$ & $56.14-63.55$ & 79.2 & $67-72$ \\
\hline Hydrogen & $10-15$ & 8.4 & $8.36-8.90$ & $8.55-8.64$ & $6.49-7.66$ & 10.0 & $86-9.1$ \\
\hline Nitrogen & $0.1-2$ & $4.4-6.9$ & $6.23-6.50$ & $6.53-6.69$ & $3.71-4.97$ & 4.7 & $1.6-6.3$ \\
\hline Oxygen & $0.05-1.5$ & $5.5-10.4$ & $14.9-16.6$ & $10.74-10.87$ & $25.08-32.40$ & 5.7 & $10-22$ \\
\hline Sulphur & $0.05-6.0$ & $\sim 0.5$ & $0.65-0.86$ & 1.21 & - & 0.5 & \\
\hline Metals & $<0.1$ & - & - & - & - & & \\
\hline Viscosity, cP & $\begin{array}{l}180(@ \\
\left.50^{\circ} \mathrm{C}\right)\end{array}$ & - & $75.15-75.26$ & & - & & \\
\hline Density, Kg/L & & 1.1 & & & & & \\
\hline $\mathrm{HHV}, \mathrm{MJ} / \mathrm{kg}$ & & & 33.2 & & $26.62-30.74$ & & \\
\hline
\end{tabular}

The nitrogen and sulphur could be converted into $\mathrm{NO}_{x}$ and $\mathrm{SO}_{x}$, respectively after combustion [14;33] and thus will contribute to air pollution. This is a serious setback considering that environmental issues are among the key reasons for biofuels development. In a recent life cycle assessment (LCA) of bio-jet fuel produced through HTL of microalgae cultivated in wastewater effluent, Fortier and colleagues [28] showed that the GHG emissions of microalgae derived bio-jet fuel can be reduced by up to $76 \%$ compared to conventional jet fuel [28].

The bio-crude also has higher concentration of water than crude oil, which makes it corrosive and thermally unstable [11]. Additionally, the HTL bio-oil has very high viscosity due the presence of long chain fatty acids. This high viscosity poses problems for its utilization in transportation applications. Therefore, upgrading the bio-crude is necessary in order to remove the heteroatoms, halogens \& metals [19]; and improve thermal stability and viscosity; to make it suitable for transportation applications [33]. Without upgrade, it can only be used as a heavy crude oil replacement for co-firing with coal [2].

The upgrade however, makes the bio-crude a good candidate for producing high quality distillate fuels, especially the middle distillates. Figure 3 shows the transformation of microalgae biomass to HTL biocrude (bio-oil),to upgraded bio-crude as a mixture of fuels (hydrotreated bio-oil), and to fractionated individual fuels.

Middle distillates fuels refer to a range of refined products condensed in the middle of the distillation column during crude oil refining [30], between the lighter fractions and heavier products of the process [29]. They are medium sized hydrocarbons which exists in liquid state, having approximately 11 to 18 carbon atoms in their molecules [30]. They typically include kerosene, distillate fuel oil and gas oil, normally used as jet fuel for aircrafts or lighting; cooking \& heating; as diesel fuel; and as home heating oil respectively $[29,30]$. 


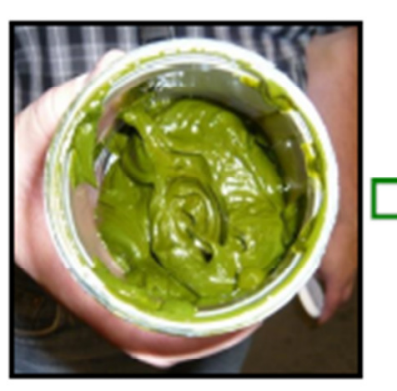

Feedstock: Wet

Nannochloropsis salina Paste

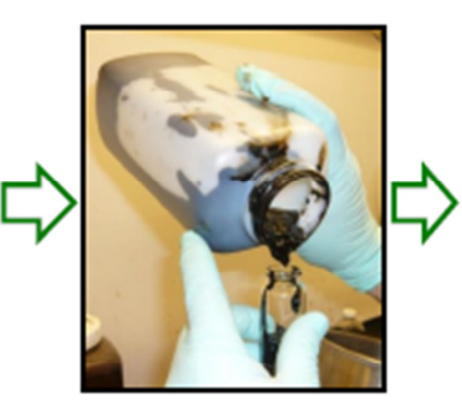

HTL Bio-Oil

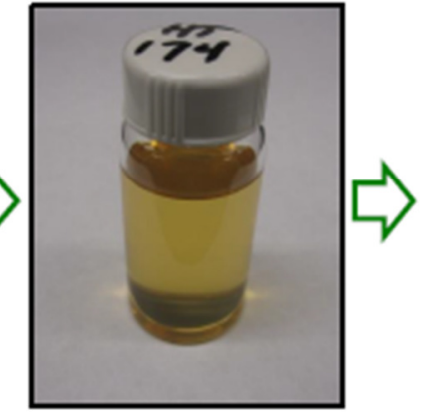

Hydrotreated HTL Bio-Oil

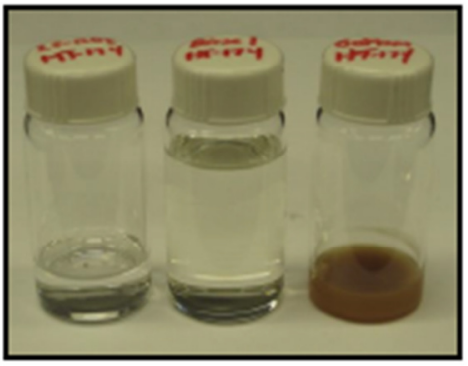

Fractionated cuts: naphtha, diesel, bottoms

Figure 3: Physical transformation of microalgae biomass to HTL bio-crude and to upgraded oil [19]

The technical path used to produce liquid fuels from bio-crudes is hydroprocessing (HDP), where the oil is reacted with hydrogen over a catalyst to produce a targeted mixture of hydrocarbons (fuels) specifically alkanes, with water, $\mathrm{CO}_{2}$ and $\mathrm{CO}$ as the by-products. The alkane mixture can then be cracked and/or fractionated to different fuels like middle distillates HRJ and HRD [34]. Both HRJ and HRD are considered drop-in fuels because they are compatible with conventional petroleum processes \& equipment; transportation and storage facilities; existing fuel infrastructure; and can be blended with petroleum products in any proportion [34].

Hydroprocessing the bio-crude is relatively convenient in the sense that it converts up to 95\% (by volume) of the bio-crude, produces primarily long chain hydrocarbons (from lipids) and smaller chains plus cyclics (from protein and carbohydrates), using commercially available technology [4]. The process is generally seen as an extension of petroleum processing and system requirements are not far outside the range of conventional hydroprocessing [16]. Furthermore, in the resulting distillate fuels performance properties are more or less equivalent to those of conventional petroleum fuels, with potentially lower greenhouse gas emissions $[17 ; 28]$.

\section{MODELLING SIMULATION AND ANALYSIS OF MIDDLE DISTILLATE FUELS PRODUCTION BY HYDROPROCESSING HTL BIO-CRUDE}

\subsection{Hydroprocessing Microalgae HTL Bio-Crude to Middle Distillate Fuels}

Hydroprocessing is a crude oil refining process which involves a number of different sub-processes, depending on the structural and compositional properties of the feeds [31], as well as the desired products. Hydroprocessing involves chemical reactions with hydrogen gas, and is typically a catalytic process operated at elevated pressure, usually to remove heteroatoms, remove unsaturation, and reduce molecular weight $[1,16]$.

For middle distillate fuels production the required hydroprocessing reactions involves hydrotreatment (HDT) and hydrocracking (HDC) processes. HDT to remove the heteroatoms; reduce the viscosity; improve the thermal stability; and increase the energy content [34]; and HDC to reduce molecular weight by cracking higher molecular weight hydrocarbons into lower ones $[16,20]$.

Typical catalysts reportedly used for hydroprocessing HTL bio-crude include $\mathrm{NiMo} / \gamma-\mathrm{Al}_{2} \mathrm{O}_{3}$ and $\mathrm{CoMo} / \gamma$ $\mathrm{Al}_{2} \mathrm{O}_{3}[18,41]$. Generally, CoMo is characterised by higher activity while NiMo is characterised by higher selectivity [41]. In a recent study [39] on the process design and economics for the conversion of whole microalgae biomass to liquid fuels via HTL and HDT, Jones et al., [39] employed CoMo/alumina-F catalyst which is commonly used in petroleum hydrodesulfurization (HDS), and known to be active for nitrogen and oxygen removal as well. In other recent developments bi-functional catalyst for example Ni/Zeolite (Hbeta, ZSM-5) have been used for upgrading microalgae derived bio-oil at $260^{\circ} \mathrm{C}, 40 \mathrm{bar}$ $\mathrm{H}_{2}$ and $78 \%$ conversion was achieved [41]. Torriet al., [38] investigated the effect of H-ZSM-5 (which is known to catalyse various reactions involving nitrogen) on the production of hydrocarbons from the HDT of oils derived from HTL of microalgae. They indicated that [38] besides the well-known deoxygenating activity, HZSM-5 can be used as an interesting way to reduce nitrogen content to acceptable limit. Their results [38] showed that the microalgae HTL bio-oil can be converted into a 
mixture of aromatic and aliphatic hydrocarbons with appreciable conversion yields [38].

\subsubsection{Hydro treatment (HDT) of Microalgae HTL Bio- Crude to Stable Oil (Hydrocarbon Mixture)}

In the HDT process, hydrogen reacts with the biocrude via a number of simultaneous chemical reactions most notably hydrodeoxygenation (HDO) and hydrodenitrogenation (HDN). HDO removes oxygen as $\mathrm{CO}_{2}$ and water, while $\mathrm{HDN}$ removes nitrogen as ammonia. Other heteroatoms (if present) like sulphur are removed via similar reactions - for example sulphur is converted to hydrogen sulphide via hydrodesulphurization, HDS [18; 19; 20; 39]. The HDO and HDN reactions results in the formation of aromatic or aliphatic hydrocarbons (having the same carbon number as contained in the feed), with small $\mathrm{C}_{1}-\mathrm{C}_{2}$ fragments and propane [18]. These n-alkanes make the resulting fuel become of higher energy contents than their precursor oil fed into the HDO process [18]. The HDO and HDN reactions also saturates double bonds, and cleave the propane backbone of any available triglycerides [17]. Figures $4 \mathrm{a}$ and $4 \mathrm{~b}$ shows some examples of HDO and HDN reactions. HDN and HDO are either achieved using two separate reactors or a two-in-one reactor with a catalyst that can selectively remove both nitrogen and oxygen.

A previous study suggest that by using a continuous operation in a single hydrotreater, oxygen content can be reduced to less than $1 \%$ and the nitrogen content to $<0.3 \%$. An example of single stage HDT is shown in Figure 5. Typical HDT conditions for microalgae derived HTL bio-crude are approximately 350 to $400^{\circ} \mathrm{C}$; and 6 to $12 \mathrm{MPa}$, [some studies suggest pressures as low as $3 \mathrm{MPa}$ for similar type feedstock) [39]. The water formed and hydrocarbons phases exiting the HDT are cooled, condensed and fractionated into four boiling point cuts: $\mathrm{C}_{4}$ minus (offgas), naphtha range (gasoline pool), diesel range (diesel pool), and heavy oil range material (to be sent to hydrocracker) [39].

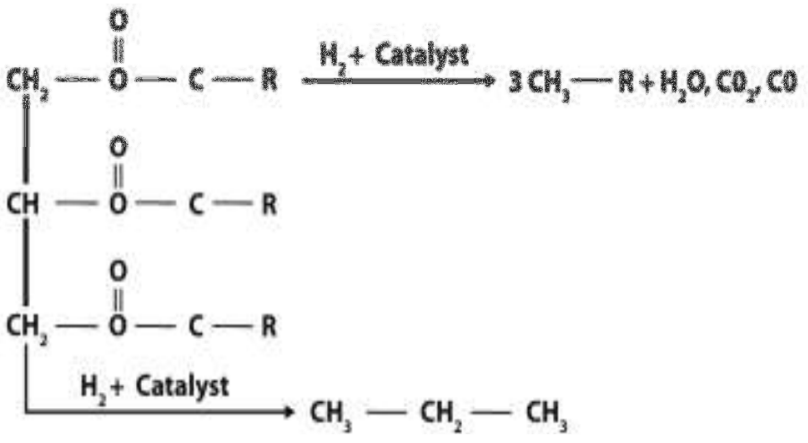

Figure 4a: Hydrotreatment reaction [34]

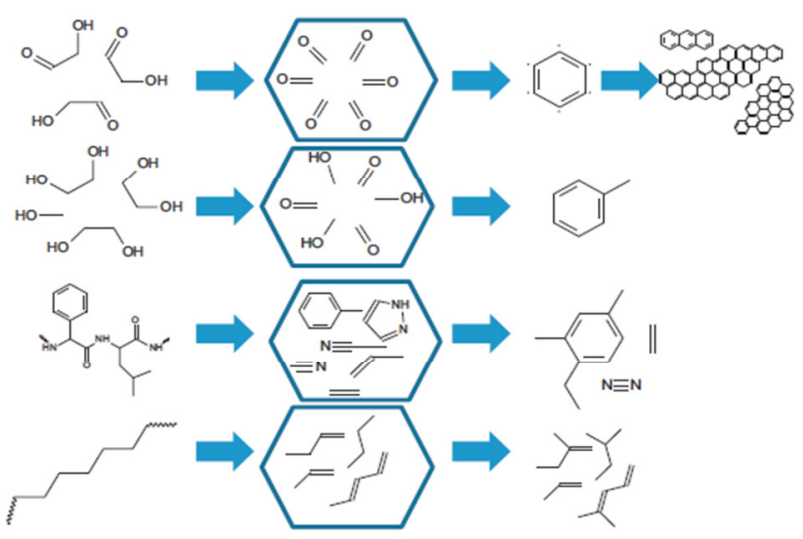

Figure 4b: Hydrodeoxygenation and hydrodenitrogenation of bio-crude [38]

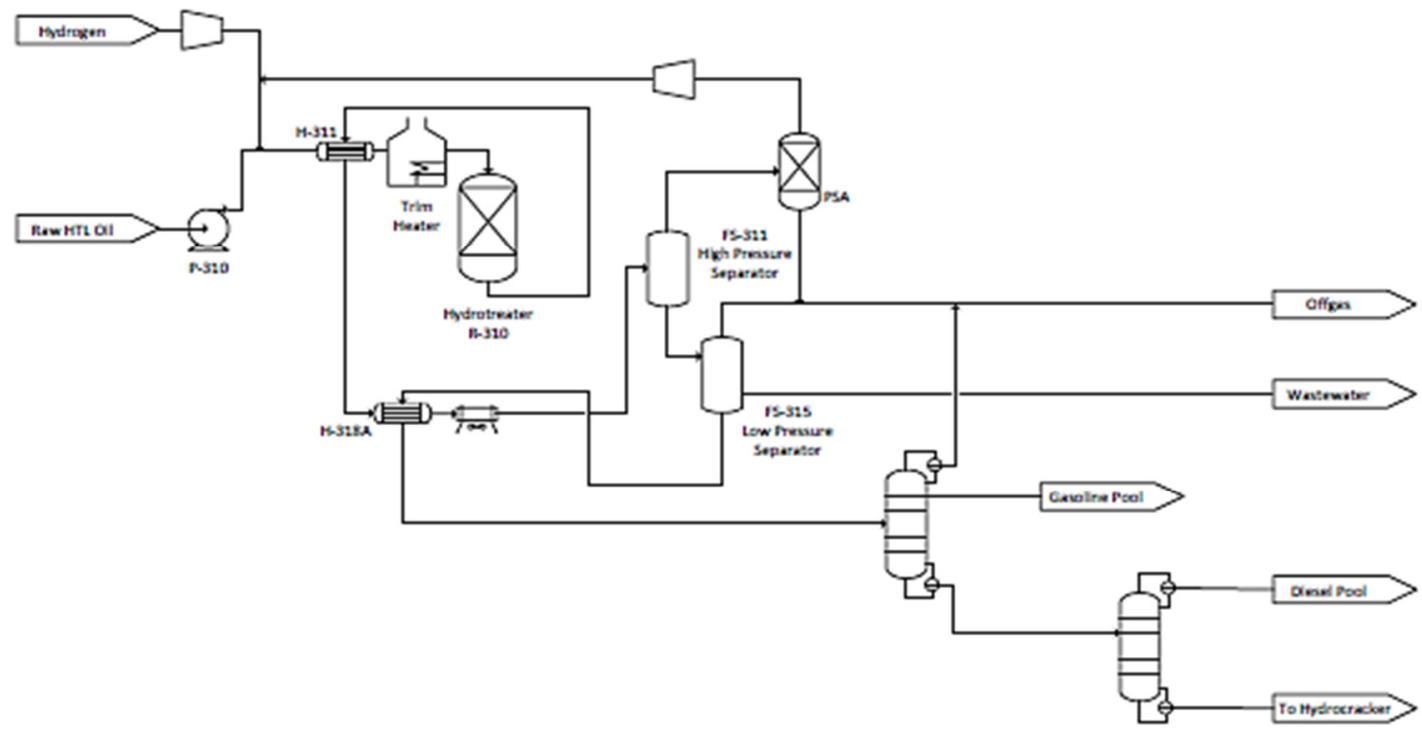

Figure 5: Process flow diagram for hydrotreating HTLbio-oil [39] 


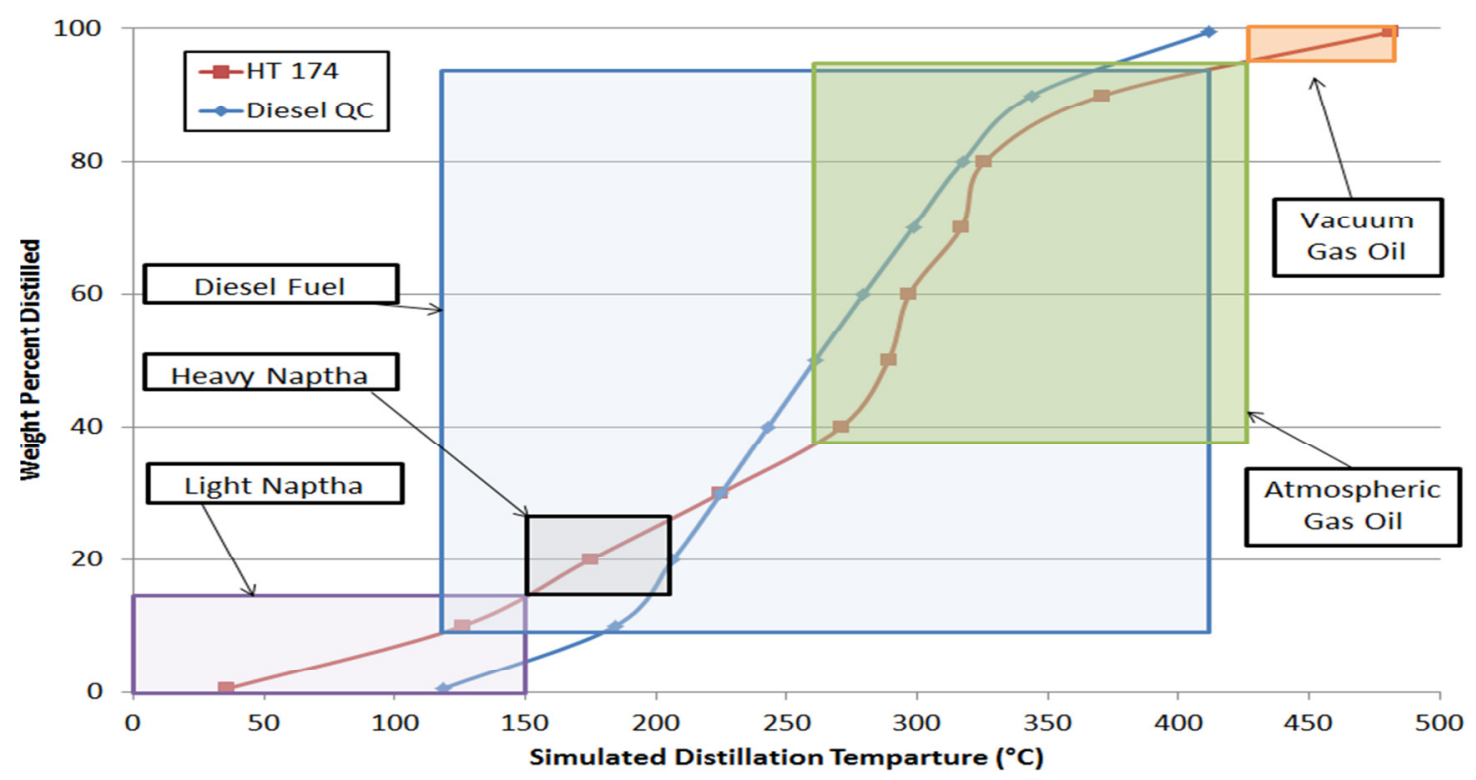

Figure 6: Typical product distribution of hydrotreated microalgae derived HTL bio-crude [19]

Generally, the chain-lengths of the hydrocarbons obtained from biological feedstock are typically $\mathrm{C}_{11}$ and above, normally $\mathrm{C}_{14}-\mathrm{C}_{22}$ [32]. The main products from HDT process composed of predominantly a wide range of straight chain alkanes of $\mathrm{C}_{9}-\mathrm{C}_{20}$ carbon range [17]. But for microalgae with relatively high lipid content (fatty acids and esters) the bio-crude will be predominantly $\mathrm{C}_{18}$ hydrocarbons. Figure 6 shows a typical product distribution from the fractionation of a hydrotreated microalgae derived HTL bio-crude [19].

Therefore, the products from HDO and HND will be mostly diesel fuel range molecules with about $15 \%$ by volume as jet/kerosene range, and minimal LPG \& naphtha as co-products. Consequently, to produce more middle distillate hydrocarbons, hydrocracking is necessary [32]. And so to the diesel range has to be cracked down to increase the volume of jet/kerosene fuel range [17]. In the hydrocracker, any desired lower chain hydrocarbon like kerosene/jet- range can be produced.

\subsubsection{Hydrocracking (Hdc) The Hydrotreated Microalgae Derived Stable Oil To Middle Distillates}

Hydrocracking is a process whereby complex organic molecules such as kerogens or heavy hydrocarbons are broken down into simpler molecules by breaking the carbon-carbon bonds [34]. It is an effective way of producing large amounts of lighter hydrocarbon products from heavier hydrocarbons, but it requires high temperatures and pressures, which are quite difficult to handle and expensive [3].
The process is normally carried out at a temperature of about $350^{\circ} \mathrm{C}$, and a pressure anywhere between 1 to $12 \mathrm{MPa}$, in the presence of a catalyst - Alumina being the most widely used [3]. Hydrocarbons heavier than diesel from the HDT unit are processed in a manner similar to conventional petroleum hydrocracking [39] to obtain jet-range fuel and naphtha. Mostly, and depending on the HDC catalyst employed, the HDC reaction occurs co-currently with selective hydroisomerization, HDI [20]. HDC creates shorter carbon chains while HDIintroduces some branching into the linear hydrocarbons [41] if required - for example to ensure that $8 \%$ by vol of kerosene range are aromatics to fulfil the requirement for its application as a jet fuel.

The HDC process can be operated to achieve any desired product distribution like maximising either of diesel fuel or jet fuel range hydrocarbons. In theory, jet-range fuel and naphtha could be created by converting $\mathrm{C}_{18} \rightarrow \mathrm{C}_{10}+\mathrm{C}_{8}$, with no additional byproducts. However, in reality the selectivity of the cracking reaction is difficult to control and the products range in size from $C_{3}$ through $C_{15}$ [17]. The lower carbon chain hydrocarbons occurring as gases are produced due to inevitable over-cracking, thereby giving a typical product breakdown of 8,86 , and $6 \%$ of gas, liquid fuel and aqueous products by weight of hydrotreated oil respectively [39].

\subsection{Modelling and Simulation of hydroprocessing HTL} bio-crude in Aspen Plus

ASPEN Plus ${ }^{\circledR}$ is a popular process simulation software widely used in the study of petrochemical processes 
and broadly adopted for the modelling, simulation and analysis of biofuel processes. The software simulates steady-state chemical process reactions and calculates mass and energy balances based on user input [1]

Huo et al. [20] conducted a modelling and simulation of HRD production from vegetable oil in Aspen Plus, to generate a material and energy balances as input for the LCA of the process. Pearson et al. [17] reviewed the HEFA (Hydroprocessing Esters and Fatty Acids) process for liquid fuels production from vegetable oils, and used Aspen Plus to conduct the material and energy balances around all the unit operations and supporting utilities. Their simulation model was designed for two product profiles i.e. maximum distillate production (which involves only HDT) and maximum jet fuel production (which involves both HDT and HDC). The maximum distillate profile was made for the production of mostly HRD while minimizing LPG and naphtha co-product, while the maximum jet profile was to produce more of HRJ by catalytically cracking diesel the range molecules. In a more recent work, Jones et al [39] used Aspen Plus to study the hydroprocessing of microalgae derived HTL bio-crude for the production of distillate fuels.

A process model in Aspen Plus consists of two sections: physical property models and unit operation models. The simulation environment on the other hand has three sections [20] i.e. the components list, where chemical species are defined; physical property option sets, where the set of physical property models to be used for the simulation are selected; and the flow sheet where the series of unit operations describing the process flow are shown. A simulation model in Aspen Plus therefore depends on the correctness of the users input in each of the stated sections.

The most challenging aspect in modelling bio-related processes is in defining the inputs to serve as components for the desired process.

\subsubsection{Hydroprocessing Simulation inputs}

To build a model for hydroprocessing the HTL biocrude to middle distillate fuels, a components list is required to be defined to represent HDT the input or bio-crude, another list as the HDT output or hydrotreated bio-crude (which will also be the feed to HDC), and finally the HDC output in the form of fuels produced.

Since the bio-crude is a complex mixture of different components [39] actual chemical species must be selected to represent constituent components. The most important thing in making the selection is that the number and type of compounds used in the Aspen Plus ${ }^{\circledR}$ model to represent any component must reasonably match several key properties such as elemental composition ( $\mathrm{C}, \mathrm{H}, \mathrm{O}, \mathrm{N}, \mathrm{S})$, quality based on GCMS data, density, and heating value [1]. Other important properties to be considered are the expected bio-crude distillation range and aqueous solubility, especially for the purpose of HDC and the subsequent fractionation of the desired fuel products. Tables 2 and 3 show the list of compounds selected and their corresponding compositions used by Jones et al. [39] in developing the Aspen model for the simulation of HDT of microalgae derived HTL biocrude to produce HRD. Each of the compounds listed and their given percentage compositions represents a group of compounds that taken together exhibit the desired bulk properties [39]. $\mathrm{C}_{18} \mathrm{H}_{38}$, which is within the range of diesel hydrocarbons [20]. The other components as by-products of the process (naphtha and LPG) are normally specified as conventional petroleum refining products.

Likewise, the final products HRD and HRJ are not specific components but complex mixtures of hydrocarbons. However, for simplicity they can be modelled like conventional corresponding fuels. For example HRD can be modelled as a single component, Huo et al. [20] specified HRD (green diesel) with a specific gravity of 0.78 and a MW of 254, and Naphtha with a specific gravity of 0.7 and a MW of 100 in their simulation. These components are registered as conventional component for the simulation.

The process flow sheet, based on the HDT process description in section 3.2.1 is shown in Figure 7, while Figure 8 shows the flow sheet for HDT of the hydrotreated oil based on the process described in section 3.2.2.

\section{EXPECTED RESULTS}

Previous studies indicate that the yield of fuels obtainable from hydroprocessing HTL bio-crude strongly depend on the exact composition of biocrude and the process conditions to a lesser extent. Theoretically, when the process is operated at optimum conditions total fuel output can be estimated from [40] the following correlation

$$
\text { Conversion } \%=\left(\frac{\text { wt of C6 }- \text { C } 24 \text { alkanes }}{\text { wt of oil input }}\right) * 100
$$

while the kerosene/jet fuel range hydrocarbons to be produced can be estimated by [40] the following 
Jet fuel selectivity, \%

$$
=\left(\frac{\text { wt of C8 }- \text { C16 alkanes }}{\text { wt of oil input }}\right) \times 100
$$

Chen [18] indicates that yield of biodiesel can be approximately $81 \%$ of the feed oil by weight or $92 \%$ by volume depending on the feed composition [18], while up to $95 \%$ by vol is suggested by another study [4]. Also other studies indicate that hydroprocessing almost all microalgae HTL oil achieved more than two thirds of the theoretical efficiency, meaning that the actual conversion effectiveness is very much close to the theoretical one [38].

Table 2: Components list and compositions as simulation inputs for the hydro treatment of bio-crude in Aspen Plus

\begin{tabular}{|c|c|c|}
\hline \multicolumn{3}{|c|}{ Source [39] } \\
\hline Compounds in Bio-crude & $\begin{array}{l}\text { Simulation } \\
\text { Name }\end{array}$ & $\begin{array}{l}\text { Composition } \\
(\mathrm{Wt} \%)^{*}\end{array}$ \\
\hline 1-ethyl-2-pyrolidinone & IE2PYDIN & 3.68490512 \\
\hline $\mathrm{N}$-methylthiopyrolidone & C5H9NS & 0.55654482 \\
\hline Ethylbenezene & ETHYLBEN & 1.37966902 \\
\hline Phenol, 4-methyl- & 4MPHYNO & 2.76367884 \\
\hline Phenol, 4-ethyl- & 4EPHYNOL & 2.76367884 \\
\hline Indole & INDOLE & 2.76367884 \\
\hline 1H-Indole, 7-methyl- & 7MINDOLE & 1.84245256 \\
\hline Myristamide (C14 amide) & C14AMIDE & 1.84245256 \\
\hline Palmitamide (C16 mide) & C16AMIDE & 8.29098226 \\
\hline Stearamide (C18 amide) & C18AMIDE & 3.68490512 \\
\hline Palmitoleic acid (C16:1FA) & C16:1FA & 7.36975598 \\
\hline $\begin{array}{l}\text { Palmitic acid } \\
\text { (Hexadecanoic acid) }\end{array}$ & C16:0FA & 5.52735768 \\
\hline Oleic acid & C18FACID & 0.92122628 \\
\hline Naphthalene & NAPHTHA & 2.76367884 \\
\hline Fused rings (Cholesterol) & CHOLESOL & 0.92122628 \\
\hline Aromatic amine & AROAMINE & 4.41806624 \\
\hline $\begin{array}{l}\text { 1,2-benzenedicarboxylic } \\
\text { acid }\end{array}$ & C30DICAD & 2.76367884 \\
\hline Methanol & METHANOL & 1.337438 \\
\hline Ethanol & ETHANOL & 13.37438 \\
\hline Acetone & ACETONE & 4.012267 \\
\hline Formic acid & FORMACID & 1.337438 \\
\hline Acetic acid & ACEACID & 9.094484 \\
\hline Glycerol & GLYCEROL & 4.146011 \\
\hline Carbondioxide & $\mathrm{CO} 2$ & 2.006156 \\
\hline Ammonia & NH3 & 0.853325 \\
\hline 3-pyridinol & 3-PYRDOL & 1.554017 \\
\hline 1-ethyl-2-pyrolidinone & IE2PYDINE & 1.337438 \\
\hline $\mathrm{N}$-methylthiopyrolidone & C5H9NS & 13.37438 \\
\hline Total & & 99.9980 \\
\hline
\end{tabular}

*the compositions were not exactly given in the reference [39] as presented here, but were deduced from there to serve the purpose here
Table 3: Component list and compositions as simulation outputs for hydrotreatment of bio-crude in Aspen Plus

\begin{tabular}{|c|c|c|}
\hline $\begin{array}{l}\text { Compounds in Hydrotreated } \\
\text { Bio-crude }\end{array}$ & $\begin{array}{l}\text { Simulation } \\
\text { Name }\end{array}$ & $\begin{array}{l}\text { Composition } \\
(\mathrm{Wt} \%)^{*}\end{array}$ \\
\hline Butane, 2-methyl- & 2MBUTAN & 0.7700 \\
\hline Pentane & N-PENTAN & 0.7700 \\
\hline Pentane, 2-methyl- & 2MPENTA & 3.1000 \\
\hline Hexane & HEXANE & 1.5500 \\
\hline Hexane, 2-methyl- & 2MHEXAN & 3.1000 \\
\hline Heptane & HEPTANE & 1.5500 \\
\hline Cyclohexane, methyl- & CC6-METH & 1.5500 \\
\hline Piperidine & PIPERDIN & 0.7700 \\
\hline Toluene & TOLUENE & 1.5500 \\
\hline Heptane, 3-methyl- & ЗМНEРТА & 1.5500 \\
\hline Octane & OCTANE & 1.5500 \\
\hline Cyclohexane, ethyl- & ETHCYC6 & 1.5500 \\
\hline Ethylbenzene & ETHYLBEN & 3.1000 \\
\hline o-Xylene & O-XYLENE & 1.5500 \\
\hline Nonane & $\mathrm{C} 9 \mathrm{H} 20$ & 1.5500 \\
\hline Cyclohexane, propyl- & PROCYC6 & 3.1000 \\
\hline Benzene, propyl- & C3BENZ & 1.5500 \\
\hline Nonane, 4-methyl- & 4MNONAN & 1.5500 \\
\hline Decane & $\mathrm{C} 10 \mathrm{H} 22$ & 4.6400 \\
\hline Benzene, butyl- & C4BENZ & 1.5500 \\
\hline Undecane & $\mathrm{C} 11 \mathrm{H} 24$ & 3.1000 \\
\hline 1-Phenyl-1-butene & $\mathrm{C} 10 \mathrm{H} 12$ & 1.5500 \\
\hline Dodecane & $\mathrm{C} 12 \mathrm{H} 26$ & 3.1000 \\
\hline $\begin{array}{l}\text { Naphthalene, } \\
\text { tetrahydro }\end{array}$ & $1234 \mathrm{NA}$ & 1.5500 \\
\hline Benzene hexyl- & C6BENZ & 1.5500 \\
\hline $\begin{array}{l}\text { Naphthalene, 1,2,3,4- } \\
\text { tetrahydro-6-methyl }\end{array}$ & $12346 \mathrm{~N}$ & 1.5500 \\
\hline Benzene heptyl- & C7BENZ & 1.5500 \\
\hline Benzene octvi- & C8BENZ & 3.1000 \\
\hline $\begin{array}{l}\text { 1,4-Cyclohexanedicarboxylic } \\
\text { acid,dimethyl ester }\end{array}$ & C10H16O4 & 1.5500 \\
\hline Pentadecane & С15H32 & 1.5500 \\
\hline Hexadecane & C16H34 & 12.3800 \\
\hline Hepdecane & C17H36 & 4.6400 \\
\hline Octadecane & C18H38 & 3.1000 \\
\hline Nonadecane & $\mathrm{C} 19 \mathrm{H} 40$ & 3.1000 \\
\hline Eicosane & $\mathrm{C} 20 \mathrm{H} 42$ & 7.7400 \\
\hline Heneicosane & $\mathrm{C} 21 \mathrm{H} 44$ & 3.1000 \\
\hline Tricosane & C18H38 & 1.5500 \\
\hline $\begin{array}{l}\text { 1,2-Benzenedicarboxylic } \\
\text { acid,diisooctyl ester }\end{array}$ & C24H3804 & 3.1000 \\
\hline Heptylundecyl phthalate & $\mathrm{C} 26 \mathrm{H} 42 \mathrm{O} 4$ & 3.1000 \\
\hline Triacontane & С30H62 & 0.1500 \\
\hline Total & & 100.06 \\
\hline
\end{tabular}

\section{Source [39]}

*the composition were not exactly given in the reference [39] as presented here, but were deduced from there to serve the purpose here

Other more optimistic studies reported mass yields of up to $85 \%$ for HTL oil derived from four different types of Nannochloropsis; ; and a similar work on Tetraselmiss showed a comparable range and less than $1 \mathrm{wt} \%$ oxygen in the product [39]. However, 
others [38] found less optimistic result, suggesting that the mass yields of total hydrocarbons from the HDT and HDC of the microalgae HTL bio-oil only ranges between $31 \%$ and $51 \%$ [38]. Table 4 shows the different percentages of fuels obtained by different studies on HDP.

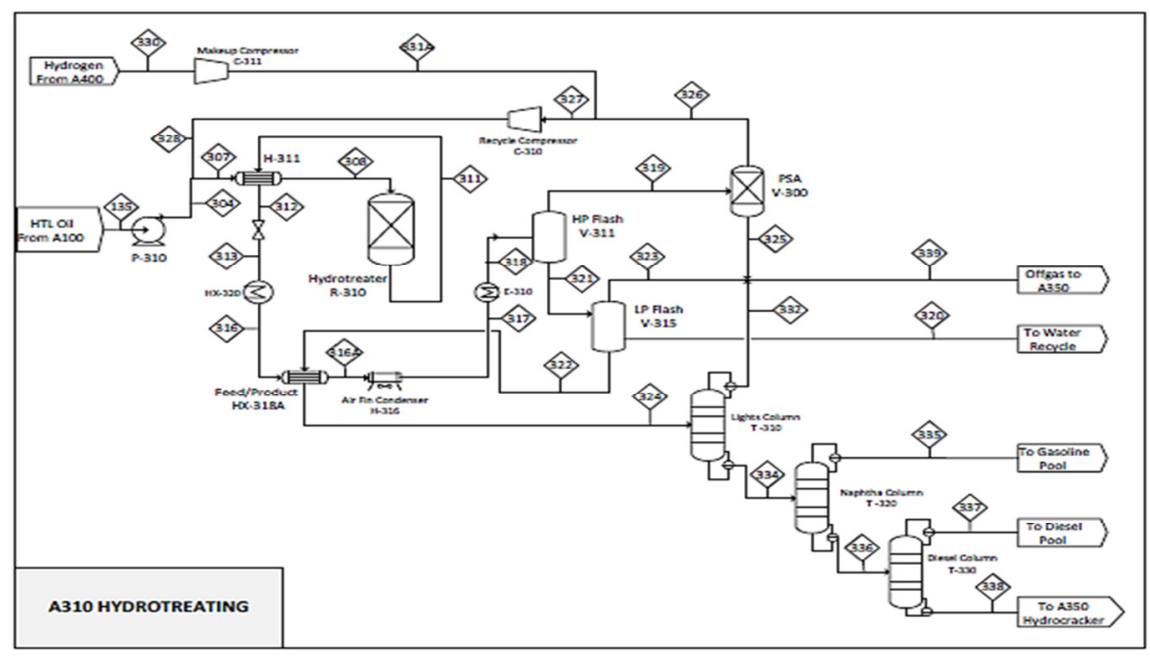

Figure 7: Aspen Plus flowsheet for the simulation of hydrotreatment of HTL bio-crude [39]

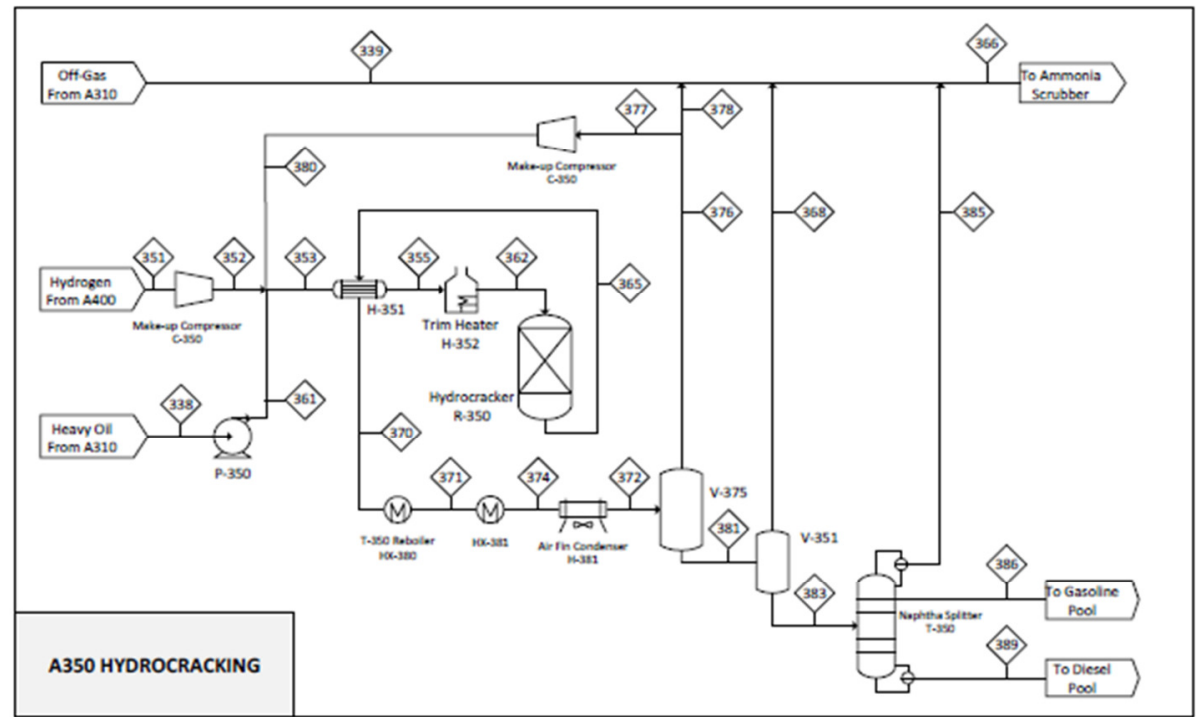

Figure 8: Aspen Plus flowsheet for hydrocracking the hydrotreated HTL bio-crude [39]

Table 4: Different simulation results for hydroprocessing microalgae HTL bio-oil

\begin{tabular}{|c|c|c|c|c|c|c|}
\hline Inputs and Outputs & $\begin{array}{c}\text { Soybean } \\
\text { oil [20] }\end{array}$ & $\begin{array}{c}\text { Soybean oil } \\
\text { (max diesel) } \\
{[17]}\end{array}$ & $\begin{array}{c}\text { Soybean oil } \\
\text { (max jet) } \\
{[17]}\end{array}$ & $\begin{array}{c}\text { Nannochloropsis } \\
\text { HTL oil [39] }\end{array}$ & $\begin{array}{c}\text { Chlorella } \\
\text { HTL oil [39] }\end{array}$ & $\begin{array}{c}\text { Algae HTL } \\
\text { oil } \\
\text { simulation } \\
\text { [39] }\end{array}$ \\
\hline \multicolumn{7}{|c|}{ Inputs (wt $\%$ of feed) } \\
\hline Oil feed & 100 & 100 & 100 & 100 & 100 & 100 \\
\hline Hydrogen & 2.73 & 2.7 & 4.0 & 5.37 & 5.8 & 5.8 \\
\hline Steam & 2.80 & & & - & - & - \\
\hline Total inputs & 105.5 & 102.7 & 104 & 105.37 & 105.8 & 105.8 \\
\hline \multicolumn{7}{|c|}{ Outputs (wt $\%$ of feed) } \\
\hline Kerozene/jet fuel range & - & 12.8 & 49.4 & 69.66 - as total & 64.5 - as total & \\
\hline Diesel blendstock & 85.18 & 68.1 & 23.3 & fuels obtained & fuels obtained & 55.18 \\
\hline Gasoline/ Naphtha & & 1.8 & 7.0 & & & 10.90 \\
\hline Propane/PFG/PMG & 5.03 & 5.8 & 10.2 & 19.48 & 19.03 & 17.26 \\
\hline $\mathrm{CO}_{2}$ & $6.98^{a}$ & 5.5 . & 5.4 & $0.75^{\mathrm{b}}$ & 0.27 & 0.3 \\
\hline Wastewater & 8.27 & 8.7 & 8.7 & 15.48 & 22 & 22.16 \\
\hline Total outputs & 105.5 & 102.7 & 104 & 105.37 & 105.8 & 105.8 \\
\hline
\end{tabular}




\section{CONCLUDING REMARKS}

The demand for bio-derived fuels is becoming more popular with time because of the need to curb environmental problems associated with the use of conventional petroleum fuels, and the increasing need to diversify the sources of transportation fuels.

This paper reviewed one of the technical routes proven to be effective for the producing a number of transportation fuels from a single feedstock synonymous to what is obtainable in conventional petroleum refining.

The key technologies involved in the HTL of microalgae to bio-crude and the subsequent upgrade of the bio-crude into middle distillate fuels via hydroprocessing were reviewed. Experimental and process simulations from previous studies were used to explore the differences \& similarities between the bio-crude and conventional crude; the methods and process conditions for hydroprocessing the bio-crude; the products obtainable, their compositions \& properties; as well as the inputs required for modelling and simulation of the process.

Consequently, it has been demonstrated that this technical route is viable for the desired application and the same fuels (of almost the same properties) can be produced from the bio-crude as obtained from petroleum crude. The outstanding difference between the hydroprocessing of microalgae derived HTL biocrude to middle distillate fuels and the hydroprocessing of conventional crude oil is the very higher hydrogen consumption. Otherwise, middle distillate fuels are produced in the same way, yielding similar quantities and with almost the same physicochemical properties as the conventional fuels.

\section{REFERENCES}

[1] Tews, I. J.; Elliott, D. C. (2014) Low-Severity Hydroprocessing to Stabilize Bio-oil: Techno Economic Assessment, PNNL-23591, The U.S. Department of Energy, Pacific Northwest National Laboratory, Richland, Washington, USA

[2] Lardon, L., Hélias, A., Sialve, B., Steyer, J., Bernard, O. (2009).Life-cycle assessment of biodiesel production from microalgae. Environ Scie and Tech. 43 (17), 6475-81

[3] Shuangning, Xiu, Bo, Zhang and AbolghasemShahbazi (2011). Biorefinery Processes for Biomass Conversion to Liquid Fuel, Biofuel's Engineering Process Technology, Dr. Marco Aurelio Dos Santos Bernardes (Ed.), ISBN: 978-953-307-480-1, In Tech,
DOI: $10.5772 / 16417$ Available from:

http://www.intechopen.com/books/biofuel-sengineering-process-technology/biorefineryprocesses-for-biomass-conversion-to-liquid-fuel (accessed on 29th Oct 2014)

[4] Genifuel, (2012). Hydrothermal processing of algae, Algae Biomass summit, 2012, Denver, Colorado, USA, September 24-27, 2012

[5] Jena, U., Das, K. C. (2009). Production of Biocrude Oil from Microalgae via Thermochemical Liquefaction Process. ASABE conference presentation, 2009 Bioenergy Engineering Conference, Hyatt Regency, Seattle, Washington, Oct 11-14, 2009

[6] Zhang, Y., 2010. Hydrothermal Liquefaction to Convert Biomass into Crude.In Blaschek, H. P., Ezeji, T. C., Scheffran, J. (Eds), Biofuels from Agricultural Waste and By-products. Blackwell Publishing. ISBN: 978-0-813-80252-7

[7] Zou, S., Wu, Y., Yang, M., Li, C., Tong, J. (2010). Bio-oil production from sub- and supercritical water liquefaction of microalgae Dunaliellatertiolecta and related properties. Energy Environ. Sci., 3, 10731078

[8] Vardon, D. R., Sharma, B. K., Scott, J., Yu, G., Wang, Z., Schideman, L., Zhang, Y., Strathmann, T. J. (2011), Chemical properties of biocrude oil from the hydrothermal liquefaction of Spirulina algae, swine manure, and digested anaerobic sludge, Bioresource Technology, 102, 8295-8303

[9] Albrecht, K., Schmidt, A., Zhu, Y., Hallen, R. (2012). Catalytic Upgrading of Intermediate Products to Hydrocarbon Fuels. Chemical and Biological process Development Group, Bioproducts, Sciences, and Engineering Laboratory, Pacific Northwest National Laboratory, Richland, WA

[10] Vardon, D. R. (2012). Hydrothermal Liquefaction for Energy Recovery from High Moisture waste Biomass. MSc Thesis, University of Illinois, Urbana, Illinois

[11] Torri, Cristian; Garcia-Alba, Laura; Samori, Chiara; Fabbri, Daniele; Brilman, Derk Willem Frederik, (2012), Hydrothermal Treatment (HTT) of Microalgae: Detailed Molecular Characterization of HTT Oil in View of HTT Mechanism Elucidation, Energy and Fuels, vol 26, no 1, pp. 658-67

[12] Duan, Peigao; Savage, Phillip E. (2011) Hydrothermal Liquefaction of a Microalga with Heterogeneous Catalysts, Industrial \& Engineering Chemistry Research, Vol 50, 2011, pp 52-61 
[13] Helmenstine, Anne Marie (2013), Chemical Composition of Petroleum, available at [http://chemistry.about.com/od/geochemistry/a/C hemical-Composition-OfPetroleum.htm] accessed on 21 august 2013

[14] Levine, R., Duan, P., Brown, T., Savage, P. E. (2010) Hydrothermal Liquefaction of Microalgae with Integrated Nutrient Recovery. Department of Chemical Engineering, University of Michigan, Ann Arbor, MI

[15] Shuping, Z., Yulong, W., Mingde, Y., Kaleem, I., Chun, L., Tong, J. (2010). Production and characterization of bio-oil from hydrothermal liquefaction of microalgae Dunaliellatertiolecta cake. Journal of Energy, 35 (12), 5406-5411

[16] Elliott, Douglas C. (2007). Historical developments in hydroprocessing bio-oil. Energy and Fuels. 21, pp 1792-1815

[17] Pearlson, M., Wollersheim, C., Hileman, J. (2013). A techno-economic review of hydroprocessed renewable esters and fatty acids for jet fuel production. Biofuels, Bioproducts and Biorefining, 7, (1), 89-96

[18] Chen, Song (2012) Green oil production by hydroprocessing, International Journal of Clean coal and energy, available at http://www.SciRP.org/journal/ijcce

[19] Marchese, Anthony. J. (2012) Fuel Properties and Pollutant Emissions from Algal Biodiesel, Algal Renewable Diesel and Algal HTL Fuels. Sustainable Bioenergy Development Center - Bioenergy at CSU Seminar October 16, 2012, available at www.engr.colostate.edu/ marchese/...12/marchese -algae-thermo.pptx [accessed 22 August 2012]

[20] Huo, H., Wang, M., Bloyd, C., Putsche, V. (2008). LifeCycle Assessment of Energy and Greenhouse Gas Effects of Soybean-Derived Biodiesel and Renewable Fuels. The U.S. Department of Energy, Office of Energy Efficiency and Renewable Energy. ANL/ESD/08-2

[21] Pearlson, M. N. (2011). A techno-economic review of hydroprocessed renewable esters and fatty acids for jet fuel production.Masters thesis, Massachusettes Institute of Technology

[22] Rinanti, A.; Kardena, E.; Astuti, D. I.; Dewi, K. (2013), Integrated Vertical Photobioreactor System for Carbondioxide Removal Using Phototrophic Microalgae, Nigerian Journal of Technology, Vol 32, no 2, pp. 225-232
[23] Ugwuishiwua, B.O.; Obib, O.F.; Nwakaire, J.N. (2013), Development of a Photobioreactor for Microalgae Culture, Nigerian Journal of Technology, Vol. 32, no.1, pp.148-151

[24] Chen,Chun-Yen; Yeh,Kuei-Ling; Aisyah, Rifka; Lee, Duu-Jong; Chang,Jo-Shu, (2011) Cultivation, photobioreactor design and harvesting of microalgae for biodiesel production: A critical review, Bioresour. Technol, Vol. 102, no.1, pp.71-81

[25] Mata,T.M.; Martins, A.A.; Caetano, Nidia.S. (2010), Microalgae for biodiesel production and other applications: A review, Renewable and Sustainable Energy Reviews, Vol 14, no. 1, pp.217-232

[26] Brennan,L.; Owende, P. (2010) Biofuels from microalgae-A review of technologies for production, processing, and extractions of biofuels and coproducts, Renewable and Sustainable Energy Reviews, Vol. 14, no. 2, pp557-577

[27] Cordon, M., Li, Z., List, T., Zhang, A. (2013). The Growth and Production of Crude Oil from Algae using Hydrothermal Liquefaction and Catalytic Hydrothermal Gasification. Bachelor Degree Thesis, Chemical Engineering Department, University of Arizona

[28] Fortier, Marie-Odile P.; Roberts, Griffin W.; StaggWilliams, Susan M.; Sturm, Belinda S.M. (2014) Life cycle assessment of bio-jet fuel from hydrothermal liquefaction of microalgae, Appl.Energy, Vol. 122, pp.73-82

[29] Vitol (2015), Middle Distillates, available at [http://www.vitol.com/what-we-do/trading/gasoil-jet/], accessed on 31 May, 2015

[30] Quora (2015), What are middle distillates?, available at [http://www.quora.com/What-aremiddle-distillates], accessed on 31 May, 2015

[31] Furimsky, Edward (2013), Hydroprocessing challenges in biofuels production, Catalysis Today, Vol. 217, pp.13-56

[32] Shi, Fan; Wang, Ping; Duan, Yuhua; Link, Dirk; Morreale, Bryan, (2012) Recent developments in the production of liquid fuels via catalytic conversion of microalgae: experiments and simulations, RSC Advances, Vol 2, pp.9727-974

[33] Guo, Yang; Yeh, Thimas; Song, Wenhan; Xu, Donghai; Wang, Shuzhong, (2015), A review of bio-oil production from hydrothermal liquefaction of algae, Renewable and Sustainable Energy Reviews, Vol 48, Pp. 776-790 
[34] Darzins, Al; Pienkos, Philips; Edye, Les (2010), Current Status and Potentials for Algal biofuels Production, T39 - T2, IEA BIOENEGY TASK 39, United States of America

[35] Zhu,Yunhua; Albrecht, Karl O.; Elliott, Douglas C.; Hallen, Richard T.; Jones, Susanne B. (2013), Development of hydrothermal liquefaction and upgrading technologies for lipid extracted algae conversion to liquid fuels, Algal Research, Vol. 2, no. 4, pp. $455-464$

[36] Jones, Susanne B.; Snowden - Swan, Lesley; Meyer, Pimphan (Aye), (2013), Bio-Oil Upgrading Economics and Sustainability, UNIVERSITY OF DELAWARE, USA, UNIVERSITY OF DELAWARE

[37] Garcia-Alba, Laura, (2013), Algae Biorefinery: An Experimental Study on Liquid Fuels Production and Nutrients Recycling, The University of Twente, University of Twente, Enscheda, The Netherlands, PhD

[38] Torri, Cristian; Fabbri, Daniele; Garcia-Alba, Laura; Brilman, Derk Willem Frederik, (2013), Upgrading of oils derived from hydrothermal treatment of microalgae by catalytic cracking over H-ZSM-5: A comparative Py-GC-MS study, J.Anal. Appl. Pyrolysis, Vol 101, pp28-34

[39] Jones, S., Davis, R.; Zhu, Y.; Kinchin, C.; Anderson, D.; Hallen, R.; Elliot, D.; Schmidt, A.; Albrecht, K.; Hart, T.; Butcher, M.; Drennan, C.; Snowden-Swan, L. (2014), Process Design and Economics for the Conversion of Algal Biomass $t$ Hydrocarbons: Whole Algae. Hydrothermal Liquefaction and Upgrading, PNNL 23227, U.S. Department of Energy, Oak Ridge, Tennessee, USA

[40] Reddy, Harvind Kumar, (2012), Production of renewable fuels from algae, $\mathrm{PhD}$, Department of Chemical Engineering, New Mexico State University, Las Cruces, New Mexico, USA, PhD.

[41] Feng, Maoqi and Erwin, Jimell (2012), Hydrotreating of Bio-oils to Jet Fuels: An Overview, AIChE 2012 Conference,October 28 - November 2, 2012, David L. Lawrence Convention Center, Pittsburgh, PA 